\title{
Models of smoking cessation brief interventions in oral health
}

\author{
Greer M. Dawson ${ }^{\mathrm{A}, \mathrm{C}}$, Jennifer M. Noller $^{\mathrm{B}}$ \\ and John C. Skinner ${ }^{\mathrm{B}}$ \\ ${ }^{\mathrm{A}}$ NSW Public Health Officer Training Program, NSW Ministry \\ of Health \\ ${ }^{\mathrm{B}}$ Centre for Oral Health Strategy, NSW Ministry of Health \\ ${ }^{\mathrm{C}}$ Corresponding author.Email: gdaws@doh.health.nsw.gov.au
}

\begin{abstract}
The links between tobacco smoking, and periodontal disease and oral cancer make the inclusion of smoking cessation interventions at dental visits an important prevention strategy in oral health services. The 5As (Ask, Advise, Assess, Assist, Arrange), which utilises a stages of change model, is the most commonly recognised framework for the provision of smoking cessation brief interventions and is advocated widely. While the popularity of the 5 As continues, increasingly evidence suggests that staged-based interventions in smoking cessation may not be the best approach. Lack of time and expertise are also cited by health professionals as barriers to undertaking brief interventions and thus abbreviated forms of the 5As have been advocated. In 2009, NSW Health introduced a mandatory policy for public dental services in NSW to conduct smoking cessation brief interventions at the chairside based on a three-step approach, which is currently being evaluated. Given the debate and the pending evaluation results, this paper reviews models of smoking cessation brief interventions, to contribute to achieving a best practice model for public oral health in NSW.
\end{abstract}

Tobacco (smoking) is recognised as a leading preventable cause of morbidity and premature mortality. Smoking greatly increases the risk of many cancers and is a major cause of chronic obstructive pulmonary disease and cardiovascular disease. ${ }^{1}$ As such, smoking continues to impose a significant burden on the health system and the economy and remains an important public health challenge. While smoking rates in Australia have decreased substantially in recent years they remain unacceptably high, particularly among Aboriginal people and people from low socioeconomic and other disadvantaged groups. ${ }^{2}$ Further reducing smoking is a key commitment of the NSW Government; robust targets have been set in order to combat chronic disease and rising health care costs. ${ }^{3}$

The causal links between tobacco smoking, and periodontal disease and oral cancer are well understood within the field of oral health. ${ }^{4}$ The inclusion of smoking cessation services in dental visits is therefore an important prevention strategy, and oral health professionals are well positioned to give cessation advice. ${ }^{5}$ In NSW, access to adult public dental care is for concession card holders only. ${ }^{6}$ The populations cared for by public oral health professionals are amongst the most disadvantaged groups in the community and have higher rates of smoking than the general population. ${ }^{3}$ As a result, smoking cessation is an issue of particular relevance to public dental services.

The World Health Organization (WHO) recommends that brief opportunistic interventions should be undertaken by all health professionals in the course of their routine work. ${ }^{7}$ Health professionals are well placed to deliver cessation advice to smokers because they are considered an important source of credible information ${ }^{8}$ and smokers also expect to receive quitting advice from health professionals. ${ }^{9,10}$ While the evidence base is stronger for some professional disciplines than others, it has been suggested that involvement of health professionals in smoking cessation should be based on factors such as access to smokers and level of brief intervention training, rather than their discipline per se. ${ }^{4}$ Moreover, the cumulative effect of smoking cessation interventions by more than one type of health professional has the potential to substantially increase readiness to quit and quitting in the population. ${ }^{11}$

Given time is a limited commodity for health professionals, brief interventions are considered a suitable approach. ${ }^{5}$ The United Kingdom's (UK) National Institute for Health and Clinical Excellence deems that brief interventions for smoking cessation are cost effective and recommends that all health professionals should refer people who smoke to an intensive support service. ${ }^{12}$

In a systematic review of physician advice for smoking cessation, Stead et al. found that a brief advice intervention is likely to increase the quit rate by $1-3 \% .{ }^{13}$ While this is a 
Box 1. The 5 As smoking cessation brief intervention ${ }^{7,14}$

Ask about and record smoking status

Advise smokers of the benefit of stopping in a personalised

and appropriate way

Assess motivation to quit (using stages of change ${ }^{a}$ model)

Assist smokers in their quit attempt

Arrange follow up

${ }^{\text {a }}$ Stages of change is a model for assessing an individual's readiness to change a variety of behaviours, including tobacco smoking According to the theory, cessation is a process rather than a discrete event and smokers may cycle through the stages of being ready to quit, quitting and relapsing. Key questions to ask include: "How do you feel about your smoking at the moment?" and "Are you ready to quit now?" Interventions can then be tailored to an individual's stage of change.

modest effect for the individual, there is potential for substantial population benefit. In order to translate this into public health benefit, the frequency with which smokers are identified and offered advice and support needs to increase. ${ }^{13}$

The 5As (Ask, Advise, Assess, Assist, Arrange) (Box 1) is the framework most commonly referred to with regard to smoking cessation brief interventions and is considered by many authorities as the gold standard. Originally developed as part of the United States (US) Department of Health's Clinical Practice Guideline in 2000 and then updated in 2008, the model proposes that smokers should be given a brief intervention to address smoking at every health consultation. ${ }^{14}$

In 2002 WHO Europe ${ }^{7}$ developed evidence-based recommendations on the treatment of tobacco dependence informed by a number of authoritative reviews and guidelines (including the US Department of Health's Clinical Practice Guideline, 2000), and these reflect the 5As approach. In the UK, guidance around smoking cessation brief interventions proposes similar steps. ${ }^{12}$ In Australia, the Royal Australian College of General Practitioners (RACGP) adopted the $5 \mathrm{As}$ as standard practice in $2004 .{ }^{15}$

While the 5As approach remains popular, there is growing evidence that suggests the use of stage-based (stages of change) interventions in smoking cessation may not be the best approach. Stage-based models of behaviour change propose that interventions that consider an individual's readiness to change will be more effective than a 'one size fits all' model. ${ }^{16} \mathrm{~A}$ systematic review of stage-based interventions for influencing smoking behaviour found that despite their widespread, uncriticised use in promoting smoking cessation there is limited evidence for their effectiveness. ${ }^{16}$ West suggests that the use of the stages of change model is likely to lead to effective interventions not being offered to people who might have responded otherwise, because the approach fails to acknowledge that behaviour change can arise from a response to a trigger, even in apparently unmotivated individuals. ${ }^{17}$ Similarly, Aveyard et al. found that when smoking cessation treatment has been offered routinely to patients, a much higher proportion accept than would be predicted by surveys of smoker's willingness to quit immediately. ${ }^{18}$

In New Zealand, this evidence has been taken into account and a three-step approach has been adopted in the form of ABC (Ask, Brief Advice, Cessation Support), which states that all people who smoke should be advised to stop smoking and supported to stop, regardless of whether or not they are interested in quitting. ${ }^{19}$ More recently the RACGP, in their smoking cessation guide for health professionals, have reviewed the $5 \mathrm{~A}$ approach to shift the emphasis away from the stages of change model because there is limited evidence to support it. ${ }^{20}$

Although the 5 As remain the most widely accepted model for smoking cessation brief interventions internationally, in practice, there are limitations. Lack of time and expertise are consistently reported by health professionals as barriers to providing smoking cessation interventions. ${ }^{21-23}$ In response to this, abbreviated forms of the 5As have been adopted. The American Dental Hygienists Association has advocated the use of a three-step approach (Ask, Advise, Refer), theorising that a referral to a tobacco Quitline could replace the need for oral health professionals to assist and provide follow-up to patients who smoke. ${ }^{24}$ A study comparing this approach with the 5 As found little conclusive evidence as to which approach was more effective. ${ }^{24}$ Trotter and Worcester found that Australian dentists are willing to ask and advise patients about smoking, but are less inclined to provide assistance or follow-up to help patients quit, and are more likely to be opportunistic rather than systematic in their approach to prevention. ${ }^{25}$ A lack of protocols or guidelines for best practice smoking cessation interventions was identified in one study as an important systemic barrier within the private dental profession. ${ }^{26}$

The NSW Health policy directive (released in 2009), Smoking cessation brief intervention at the chairside: role of public oral health/dental services ${ }^{27}$ sets out the minimum requirements for public oral health staff to ask about and record smoking status, and to provide and record cessation advice and referral as appropriate. This model follows a 3As approach (Ask, Approach, Advise) (Box 2) but still advocates undertaking a stages of change assessment. Developed under the auspices of the NSW Oral Health Promotion Network, the policy is accompanied by a comprehensive training package which has been rolled out in public dental services across NSW. The Australian Schedule of Dental Services and Glossary, ${ }^{28}$ which is the 


\section{Box 2. The 3 As smoking cessation brief intervention ${ }^{27}$}

Ask about and record smoking status

Approach smokers about their interest in quitting (using stages of change ${ }^{a}$ model)

Advise of NSW Quitline and refer as appropriate

${ }^{\text {a }}$ Stages of change is a model for assessing an individual's readiness to change a variety of behaviours, including tobacco smoking. According to the theory, cessation is a process rather than a discrete event and smokers may cycle through the stages of being ready to quit, quitting and relapsing. Key questions to ask include: "How do you feel about your smoking at the moment?" and "Are you ready to quit now?" Interventions can then be tailored to an individual's stage of change.

universally accepted coding system for dental treatment in Australia, currently has no item number for provision of smoking cessation advice. Item number 191 was therefore introduced alongside the policy to record 'smoking cessation advice given' in the Information System for Oral Health (ISOH), an integrated database to support service delivery in NSW public dental clinics. This item number could potentially be used as a measure of how the policy is being implemented.

A policy implementation evaluation is currently being undertaken by the Centre for Oral Health Strategy, NSW Ministry of Health. The evaluation will review the delivery of the training package and the implementation of the policy, with a particular focus on the factors that mediate policy utilisation and outcomes. While the evaluation does not have the capacity to tell us how effective the 3As approach is compared with the $5 \mathrm{As}$, it will offer important insights into the previously unexplored area of chairside smoking cessation interventions in public oral health in NSW.

Review of the literature indicates that smoking cessation interventions in health care are varied, but tend to follow either a three- or five-step model. However, as there is little in the way of conclusive evidence demonstrating the effectiveness of one intervention over the other it is difficult to draw a definitive conclusion about what a best practice model should look like. As illustrated in this paper, there are several factors to consider in constructing an intervention model that is both theoretically sound and practically useful, but in order to have any significant impact on population quit rates interventions need to be implemented with high frequency. As clinical time priorities are often a constraint for oral health professionals, keeping interventions brief and simple is critical and the literature suggests that less emphasis should be placed on the staged approach. The results from the pending evaluation should provide insight into the tensions and realities of delivering chairside smoking cessation interventions and further contribute to refining a best practice model that is relevant to public oral health in NSW.

\section{Acknowledgments}

This work was completed while Greer Dawson was a trainee on the NSW Public Health Officer Training Program, funded by the NSW Ministry of Health. She undertook this work while based at the Centre for Oral Health Strategy, NSW Ministry of Health.

\section{References}

1. U.S. Department of Health and Human Services. The health consequences of smoking: a report of the Surgeon General. Atlanta: U.S. Department of Health and Human Services, Centers for Disease Control and Prevention, National Center for Chronic Disease Prevention and Health Promotion, Office on Smoking and Health; 2004

2. Australian Institute of Health and Welfare. Australia's health 2012. Australia's health series no. 13. Cat. no. AUS 156. Canberra: AIHW; 2012

3. NSW Ministry of Health. NSW Tobacco Strategy 2012-2017. Sydney: NSW Ministry of Health; 2012.

4. Johnson GK, Hill M. Cigarette smoking and the periodontal patient. J Periodontol 2004; 75(2): 196-209. doi:10.1902/ jop.2004.75.2.196

5. Davis JM. Tobacco cessation for the dental team: a practical guide part II: evidence-based interventions. J Contemp Dent Pract 2005; 6(4): 178-86.

6. NSW Department of Health. Oral Health-Eligibility of Persons for Public Oral Health Care in NSW. Sydney: NSW Department of Health; 2009.

7. Raw M, Anderson P, Batra A, Dubois G, Harrington P, Hirsch A et al. WHO Europe evidence based recommendations on the treatment of tobacco dependence. Tob Control 2002; 11(1): 44-6. doi:10.1136/tc.11.1.44

8. NSW Department of Health. "Let's take a moment" quit smoking brief intervention - a guide for all health professionals. Sydney: NSW Department of Health; 2005.

9. Butler CC, Pill R, Stott NC. Qualitative study of patients' perceptions of doctors' advice to quit smoking: implications for opportunistic health promotion. BMJ 1998; 316(7148): 1878-81. doi:10.1136/bmj.316.7148.1878

10. Rikard-Bell G, Donnelly N, Ward J. Preventive dentistry: what do Australians patients endorse and recall of smoking cessation advice by their dentists? Br Dent $J$ 2003; 194(3): 159-64. doi:10.1038/sj.bdj.4809899

11. An LC, Foldes SS, Alesci NL, Bluhm JH, Bland PC, Davern ME et al. The impact of smoking-cessation intervention by multiple health professionals. Am J Prev Med 2008; 34(1): 54-60. doi:10.1016/j.amepre.2007.09.019

12. National Institute for Health and Clinical Excellence. Brief interventions and referral for smoking cessation in primary care and other settings. Available at: http:/www.nice.org.uk/ nicemedia/pdf/PH001_smoking_cessation.pdf (Cited 20 October 2013)

13. Stead LF, Bergson G, Lancaster T. Physician advice for smoking cessation. Cochrane Database Syst Rev 2008; (2): CD000165. 
14. Fiore MC, Jaén CR, Baker TB, Bailey WC, Benowitz NL, Curry SJ et al. Treating tobacco use and dependence: 2008 update. Clinical practice guideline. Rockville, MD: US Department of Health and Human Services; 2008.

15. Zwar N, Richmond R, Borland R, Stillman S, Cunningham M, Litt J. Smoking cessation guidelines for Australian general practice. Aust Fam Physician 2005; 34(6): 461-6.

16. Riemsma RP, Pattenden J, Bridle C, Sowden AJ, Mather L, Watt IS et al. Systematic review of the effectiveness of stage based interventions to promote smoking cessation. BMJ 2003; 326 (7400): 1175-7. doi:10.1136/bmj.326.7400.1175

17. West R. Time for a change: putting the Transtheoretical (Stages of Change) Model to rest. Addiction 2005; 100(8): 1036-9. doi:10.1111/j.1360-0443.2005.01139.x

18. Aveyard P, Begh R, Parsons A, West R. Brief opportunistic smoking cessation interventions: a systematic review and metaanalysis to compare advice to quit and offer of assistance. Addiction 2012; 107(6): 1066-73. doi:10.1111/j.13600443.2011.03770.x

19. New Zealand Ministry of Health. New Zealand smoking cessation guidelines. Available at: http://www.health.govt.nz/ publication/new-zealand-smoking-cessation-guidelines (Cited 20 October 2013).

20. Zwar N, Richmond R, Borland R, Peters M, Litt J, Bell J et al. Supporting smoking cessation: a guide for health professionals. Melbourne: The Royal Australian College of General Practitioners; 2011.

21. Richmond R, Zwar N, Borland R, Stillman S, Cunningham M, Litt J et al. Smoking cessation for Australian general practice evaluation of best practice guidelines. Aust Fam Physician 2005; 34(6): 505-7.
22. Stacey F, Heasman PA, Heasman L, Hepburn S, McCracken GI, Preshaw PM. Smoking cessation as a dental intervention - views of the profession. Br Dent J 2006; 201(2): 109-13. doi:10.1038/ sj.bdj. 4813847

23. Watt RG, McGlone P, Dykes J, Smith M. Barriers limiting dentists' active involvement in smoking cessation. Oral Health Prev Dent 2004; 2(2): 95-102.

24. Gordon JS, Andrews JA, Crews KM, Payne TJ, Severson HH, Lichtenstein E. Do faxed Quitline referrals add value to dental office-based tobacco-use cessation interventions? J Am Dent Assoc 2010; 141(8): 1000-7.

25. Trotter L, Worcester P. Training for dentists in smoking cessation intervention. Aust Dent J 2003; 48(3): 183-9. doi:10.1111/ j.1834-7819.2003.tb00030.x

26. Edwards D, Freeman T, Roche AM. Dentists' and dental hygienists' role in smoking cessation: and examination and comparison of current practice and barriers to service provision. Health Promot J Austr 2006; 17(2): 145-51.

27. NSW Department of Health. Smoking cessation brief intervention at the chairside: role of public oral health/dental services. Sydney: NSW Department of Health; 2009.

28. Australian Dental Association Incorporated. The Australian Schedule of Dental Services and Glossary. 10th edition. Sydney: Australian Dental Association Inc; 2013. 